\title{
Evaluating the impact of nutrient abatement measures on the ecological status of coastal waters: a Bayesian network for decision analysis
}

\author{
Annukka Lehikoinen* \\ Fisheries and Environmental Management Group, \\ Department of Environmental Sciences, \\ University of Helsinki c/o Kotka Maritime Research Institute, \\ Heikinkatu 7, FI-48100, Kotka, Finland \\ E-mail: annukka.lehikoinen@helsinki.fi \\ *Corresponding author

\section{Inari Helle, Eveliina Klemola, Samu Mäntyniemi and Sakari Kuikka}

Fisheries and Environmental Management Group,

Department of Environmental Sciences,

University of Helsinki,

P.O. Box 65, FI-00014, Finland

E-mail: inari.helle@helsinki.fi

E-mail: eveliina.klemola@helsinki.fi

E-mail: samu.mantyniemi@helsinki.fi

E-mail: sakari.kuikka@helsinki.fi

\section{Heikki Pitkänen}

Marine Research Centre,

State of the Marine Environment Unit,

Finnish Environment Institute,

P.O. Box 140, FI-00260, Helsinki, Finland

E-mail: heikki.pitkanen@ymparisto.fi

\begin{abstract}
Environmental managers must make decisions about complex problems that have a high degree of uncertainty such as, which nutrient abatement measure optimally improves the condition of an ecosystem. Although data and models that provide information on this subject exist, their knowledge may be fragmentary and difficult to interpret. We present a user-friendly modelling tool that integrates results of different models and data-analyses. It can be used by decision-makers for assessing the probabilities of different nutrient abatement scenarios for achieving specific targets set by the Water Framework Directive for Finnish coastal waters in the Gulf of Finland. The results suggest that significant reductions in nutrient loads are required to achieve good ecological status in Finnish coastal waters, and in the event of increased precipitation these targets may be less likely to be attained. Moreover, different approaches to the status classification lead to very different conclusions.
\end{abstract}


Keywords: Bayesian networks; water framework directive; ecological status classification; ESC; decision analysis; multi-criteria decision analysis; MCDA; nutrient abatement; uncertainty; eutrophication; the Baltic Sea; the Gulf of Finland; GoF.

Reference to this paper should be made as follows: Lehikoinen, A., Helle, I., Klemola, E., Mäntyniemi, S., Kuikka, S. and Pitkänen, H. (2014) 'Evaluating the impact of nutrient abatement measures on the ecological status of coastal waters: a Bayesian network for decision analysis', Int. J. Multicriteria Decision Making, Vol. 4, No. 2, pp.114-134.

Biographical notes: Annukka Lehikoinen is a doctoral candidate at the University of Helsinki. Her research interests include Bayesian modelling and Bayesian networks as tools in multi-disciplinary risk assessment and management in aquatic ecosystems, particularly the brackish water ecosystem of the Gulf of Finland.

Inari Helle is a doctoral candidate at the University of Helsinki. Her research interests include environmental risk analysis and modelling of population dynamics by using Bayesian methods.

Eveliina Klemola is a Research Coordinator at the University of Helsinki. Her main research area of interest is Baltic Sea ecology.

Samu Mäntyniemi is a Professor at the University of Helsinki. His research interests include Bayesian methods in environmental decision making, such as fisheries stock assessment, constructing probability models from existing knowledge, eliciting expert's probabilities, Bayesian decision analysis and management strategy evaluation, as well as Bayesian computation.

Sakari Kuikka is a Professor of Fisheries Science at the University of Helsinki and the Head of the Fisheries and Environmental Management Research Group. His research interests include multidisciplinary analysis of fisheries systems, decision, risk and uncertainty analysis in fisheries and environmental management problems, climatic change impacts and environmental impact analysis.

Heikki Pitkänen is a Unit Leader at the Marine Research Centre of Finnish Environment Institute, Marine Environment Unit. He is specialised on the eutrophication of the Baltic Sea, internal and external nutrient fluxes, joint research projects of the Gulf of Finland and research cooperation within the Baltic Sea area.

This paper is a revised and expanded version of a paper entitled 'Probabilistic assessment tool for the water framework directive: application to the Gulf of Finland' presented at ICES Annual Science Conference 2010 in Nantes, France 20-24 September 2010

\section{Introduction}

Environmental management issues are multifaceted and require the adoption of a long-term perspective (Sigel et al., 2010). A common problem is that the knowledge available for environmental managers is often fragmentary, non-systemised and even 
inconsistent. Hence, there is a need to develop scientific decision support methods that are capable of integrating available knowledge in a way that enables the evaluation of impacts of different management policies in a user-friendly manner. Furthermore, such support methods should address the different types of uncertainties that arise from various management policies in a systematic and transparent way in order to give the decision-makers realistic pictures of those uncertainties (Burgman, 2005; Power and McCarty, 2006; Sigel et al., 2010). Even though this need is widely recognised, the proposed solutions are scarce.

Ecological status classification (ESC) of the Water Framework Directive (WFD) (European Commission, 2000) aims for the harmonised evaluation and management of inland and coastal watersheds of Europe. The target state of, 'good ecological status' by the year 2015, provides a clear minimum objective. If the state of the watershed is judged moderate or worse, remedial actions should be taken to improve the state. A 'good' classification status of an ecosystem is defined in terms of certain measurable indicators. The member states of the European Union are independently responsible for the planning and implementation of the directive, and only general guidance documents are provided. The differences between national approaches can cause problems especially regarding coastal waters, where the state of the ecosystem depends on the whole catchment area, which may be shared by several countries. Consequently, it is essential to attain a consensus between neighbouring states about the current status of any shared area of coastal waters. In addition, the clear, measurable definition of the concurrent and target ESCs between neighbouring countries must be harmonised to be able to agree upon the necessary restorative actions. A powerful decision analysis tool would be useful for estimating the ecosystem responses that the implementation of certain policies would be likely to produce. The analysis tool should also be capable of detecting the origins of differences in the results, and also be able to evaluate the uncertainties related to each issue.

We present a user-friendly solution that integrates information about complex processes. More specifically, this solution is a prototype of a decision analysis tool that can be used to assess the probabilities of reaching certain ecological objectives set by the WFD in Finnish coastal waters of the Gulf of Finland (GoF) by the target year of 2015. The model is a Bayesian network (BN) that integrates results from nutrient load and ecosystem models and data-analyses, for a range of alternative nutrient abatement scenarios in Finland, Estonia and Russia. Thus, the BN is used as a meta-model that integrates knowledge from several sources. The climate change input component of the model is 'a change in precipitation' and was included as an external, uncontrollable factor (Fenton and Neil, 2001), which causes additional uncertainty about the system.

The multi-criteria aspect of the model reflects the ecological status of the coastal waters. The multiple criteria are defined in terms of the number of indicators that represent the physical, chemical and biological components of the system. Each indicator has five states that range from 'bad' to 'high'. The current classification practices handle these states as known and without any uncertainty in their boundary values (Vuori et al., 2009). We present both the indicator-specific and general statuses as probability distributions. We also studied different approaches to define the general WFD ESC of the area, and discuss the magnitude of the uncertainties related to different aspects of the criteria under various settings. 


\section{Materials and methods}

\subsection{Study area}

The GoF is the easternmost basin of the brackish Baltic Sea and it is surrounded by the land masses of Finland, Estonia and Russia. Today the GoF is one of the world's most stressed sea areas. The nutrient loading is two to three times higher than the mean loading per area of the whole Baltic Sea (HELCOM, 2005). The shallowness and slow water exchange make the GoF especially vulnerable to the adverse effects of eutrophication. The GoF is widely studied, and several long-term monitoring data sets exist (Elken et al., 2003 ) in addition to flow and ecosystem models developed for the same area (Kiirikki et al., 2001, 2006; Soomere et al., 2008). The Finnish coastal waters of the GoF were divided according to the implementation of the WFD into four zones for these analyses (Figure 1).

Figure 1 The Finnish WFD areas in the GoF (see online version for colours)

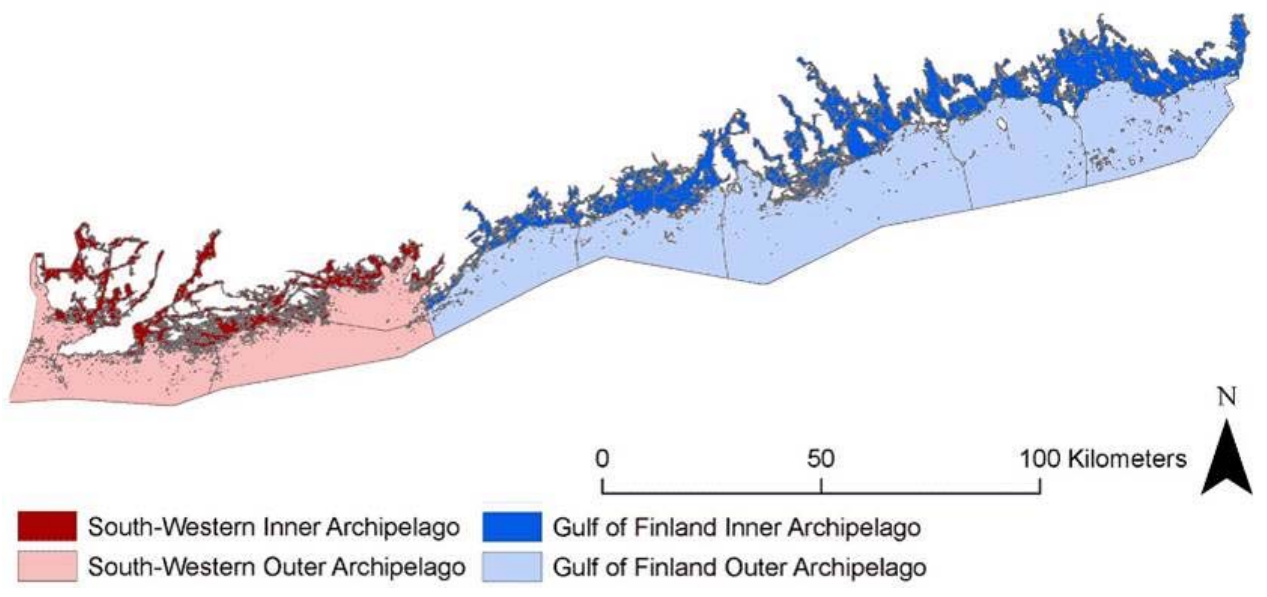

Notes: South-Western inner archipelago (area 1), GoF inner archipelago (area 2), South-Western outer archipelago (area 3) and GoF outer archipelago (area 4).

\subsection{BNs and influence diagrams}

BNs are models that are used for reasoning under conditions of uncertainty. The networks compute updated beliefs about (unobserved) events on the basis of prior observations of other events (Kjærulff and Madsen, 2005). They have been used for modelling complex environmental questions and interactions that contain large uncertainties (Reckhow, 1999; Borsuk et al., 2004; Lehikoinen et al., 2013). They have also been used for decision analysis under conditions of uncertainty (Varis et al., 1990; Kuikka and Varis, 1997; Uusitalo et al., 2005).

A BN consists of a finite set of variables and a range of probabilistic dependencies between those variables (Jensen, 2001; Kjærulff and Madsen, 2005). In the graphical representation of a $\mathrm{BN}$, the variables are denoted by nodes and the conditional dependencies by arrows. More detailed information on BNs can be found, e.g., in Jensen (2001). 
There are several alternative ways to specify and compile a $\mathrm{BN}$ that range from simulations and data-analyses (Gilks et al., 1994; Mäntyniemi, 2006; Dorner et al., 2007) to interviews about the degrees of belief of one or more experts (Uusitalo et al., 2005; O'Hagan et al., 2006; Lehikoinen et al., 2013; Mäntyniemi et al., 2013). In this study, the conditional probabilities are specified by using existing simulation models described below and learning the dependencies from the simulated datasets.

The BNs that are used for decision-making under uncertainty are called Bayesian influence diagrams (BIDs) (Kjærulff and Madsen, 2005). These are BNs augmented by decision variables including alternative actions to take, and utility functions that specify certain preferences regarding the output. A BID computes the expected utilities of all combinations of the decision options under a specified state of uncertainty at the time of the decision. The objective is to identify the combination of the actions that produce the maximum expected utility (MEU). MEU can be regarded as the fundamental idea of decision theory. In order to achieve MEU, a decision is rational only when the selected action is the one that yields the highest expected utility averaged over all the possible outcomes of the action (Dorner et al., 2007).

BIDs have been applied in the context of many environmental issues (Varis, 1997; Borsuk et al., 2004; Aguilera et al., 2011; Chen and Pollino, 2012). BNs and BIDs are also accessible to use by non-specialists because they are clear, understandable and their interpretation is relatively easy to convey to decision-makers who have no modelling experience (Cain et al., 2003; Aguilera et al., 2011). They enable the integration of the information sets of different forms and with different levels of precision into a single analysis and the assessment of the origin, type and magnitude of the uncertainties related to the cause-and-effect relationships and decisions (Bromley et al., 2005; Lehikoinen et al., 2013). Their efficiency and speed in scenario exploration are found to be unchallenged (Dorner et al., 2007).

Fenton and Neil (2001) have reviewed the use of BNs specifically for multi-criteria decision analysis (MCDA) purposes and stated that BNs enable users to overcome some critical limitations that conventional MCDA techniques have. For example, BNs allow users to handle the criteria as uncertain and facilitate linking them with each other when the corresponding real world dependence actually exists (Fenton and Neil, 2001). Despite these positive attributes and BN MCDA frameworks suggested by Watthayu and Peng (2004) and Sedki et al. (2010), we managed to find only two actual published management applications (Dorner et al., 2007; Pinheiro et al., 2008) by using the keywords BNs and MCDA.

\subsection{Structure of the model}

The main aim of our present study was to create a probabilistic decision analysis model, which combines results from separate loading model, ecosystem model and data analyses. We used BN software (Hugin Expert ${ }^{\circledR}$, Madsen et al., 2005) to build a meta-model that can be used as a decision support tool. This tool was designed to assist in the evaluation of the expected utilities ascribed to a range of different decisions about nutrient abatement measures that could be implemented in coastal countries of the GoF. The utility function was defined in terms of the WFD objectives: whether they will be attained or not. 
Figure 2 (a) The structure of the main BID for Finnish coastal waters (b) The area sub-model (c) The $F$. vesiculosus sub-model (see online version for colours)

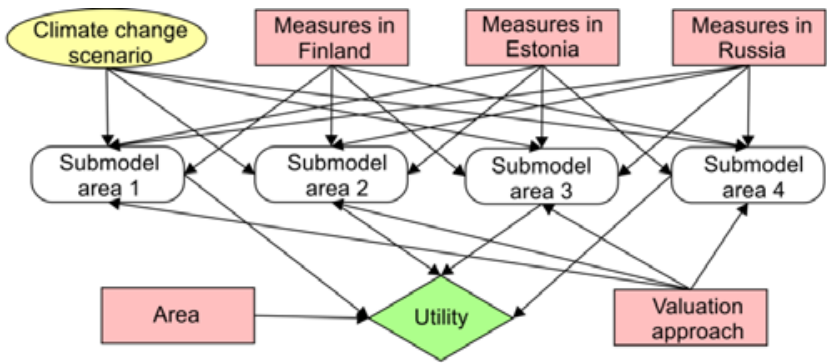

(a)

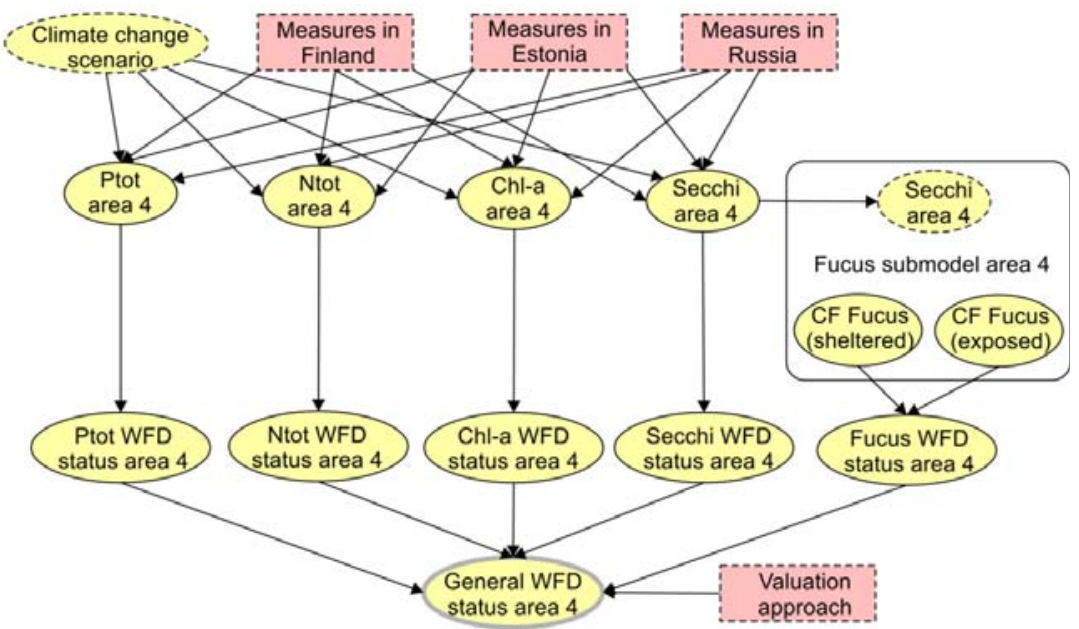

(b)

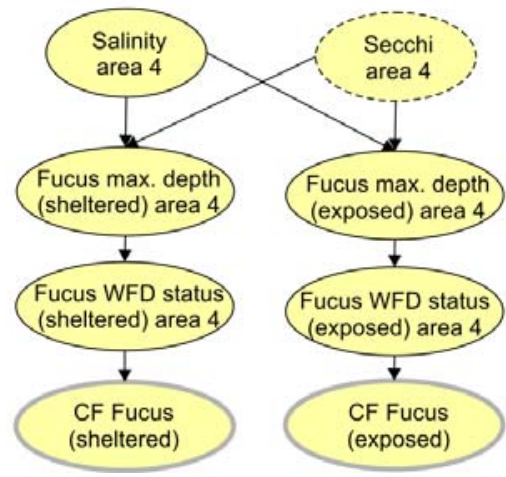

(c)

Notes: Area 4 (GoF outer archipelago) is used as an example, the sub-model structures are identical between the areas (area 2 for which Ptot is not used as indicator is the only exception). Decision variables are depicted by pink rectangles, random variables by yellow oval nodes and utility function is shown as a green diamond. In sub-models, the input and output nodes are labelled with dashed (input) or solid grey (output) edges. 
The model includes a decision node for each of the three neighbouring countries with coasts that surround the GoF (Figure 2). The alternative states are the selected nutrient abatement scenarios. The fourth input node for the network is the random variable of 'climate change' and it has two alternative states for precipitation ('current' and 'increased'). Two additional decision nodes enable a comparison of the different water zones and alternative valuation approaches (described below) with a single model.

Each area/zone has its own sub-model, which includes information on the likely ecosystem response and the following WFD status given the decisions made. The variables of interest include total nitrogen and total phosphorus in the surface layer of water in winter (January-March) and chlorophyll-a (chl-a) concentration and Secchi depth in late summer (July-August). In addition, each area has a separate sub-model that describes the maximum growth depth of the macroalgae Fucus vesiculosus. These variables are used as indicators of ecological status in the Finnish approach to meeting WFD ESC requirements (Vuori et al., 2009). All the indicator variables have five possible states: 'high', 'good', 'moderate', 'poor' and 'bad'. For discretising the variables, the area-specific class boundaries provided in the Finnish WFD classification guidelines were used as each area has unique boundaries that are based on their different natural conditions and reference values. The reference values are based on historical and present-day data (chl- $a$ and Secchi depth), literature and expert knowledge (the maximum growth depth of $F$. vesiculosus) and frequency distribution data (nutrients) (Vuori et al., 2009).

\subsection{Management scenarios and load modelling}

The modelling was based on nine different nutrient loading abatement scenarios in the GoF: four for Finland, three for Russia and two for Estonia (Table 1). In the future, precipitation is predicted to increase over the Baltic Sea area due to anthropogenic climate change (BACC Author Team, 2008), thus a scenario that represents the increased precipitation, was constructed by using data obtained from two exceptionally rainy years: 2000 and 2005 (Lindén et al., 2008). Eventually, the total number of scenario combinations was 48. The current state for Finland was based on riverine discharges and coastal point sources for the years 2000-2006, and the three water protection scenarios were formed basing on the work of Rekolainen et al. (2006). In the case of Estonia, the current loading was based on that found for the years 2000-2003 (data provided by the Estonian Marine Institute, University of Tartu), whereas the future scenario was proposed by Pitkänen and Tallberg (2007). In the case of Russia, data that represent the year 2000 was used as a current state (Pitkänen and Tallberg, 2007), and the scenarios were designed by using expert judgment.

The catchment model PolFlow was used to approximate the future load to the GoF. The PolFlow model (De Wit, 2001) describes sources, transport and loads of nutrients in large drainage basins. It comprises a hydrological component, a description of nutrient sources, a description of their pathways to the surface waters and transport of nutrients to the river mouths. The increased precipitation was simulated by running the model with the combined loads measured during the rainy years of 2000 and 2005.

It is noteworthy that in addition to the assumption of increased nutrient loads from agriculture the Estonian scenario 'increased agricultural load' (EST1) includes an evaluated decrease in phosphorus load that has resulted from the ongoing improvements in manure handling. This makes the estimated phosphorus load of 47 tons/year lower in 
this scenario than in the current state (EST0). For more detailed information on the scenarios formed and the PolFlow runs executed, see Lindén et al. (2008).

Table 1 Nitrogen (N) and phosphorus (P) loading scenarios used as mutually exclusive policy alternatives in the country-specific decision nodes

\begin{tabular}{lcc}
\hline Finland & Russia & Estonia \\
\hline Current state (FINO) & Current state (RUSO) & Current state (ESTO) \\
Business as usual: & Current treatment facilities & N and P loads increase by 10\% \\
$-15 \%$ reduction in the & increase purification efficacy & due to increased agricultural \\
P and N loads (FIN1) & for P to 80\% (RUS1) & production (EST1) \\
Realistic: $-30 \%$ & All municipal waste waters treated & - \\
reduction in the & with purification efficacy of 75\% & \\
P and N loads (FIN2) & for N and 80\% for P (RUS2) \\
Optimistic: $-40-50 \%$ & - & \\
reduction in the & & \\
P and N loads (FIN3) & & \\
\hline
\end{tabular}

\subsection{Ecosystem models}

The EIA-SYKE ecological model (Kiirikki et al., 2001, 2006) simulates dissolved nutrients and algal biomass. It was used for modelling the state of the indicator variables under different loading scenarios. The model was run for the same five-year period (1995-1999) for which it was calibrated and validated. Total nutrients were estimated from the modelled dissolved nutrients at the end of March by assuming stable, scenario-specific loading during those five years. Total phosphorus was not used for the inner archipelago area 2 (Vuori et al., 2009).

The EIA-SYKE is a deterministic 3D-model, and it simulates spatial point estimates for the specified grid cells. Scenario-specific areal probability distributions of the indicators were produced by using the spatial variability within a specified area as a source of uncertainty. A simulation data file was created, whereby the surface value of each of the $5 \times 5 \mathrm{~km}$ squares in the ecosystem model grid within the area in question was treated as a possible observation. Therefore, as the numbers of data points varied from 25 in area 1 to 125 in area 4, the variability in the resulting distributions corresponded to the size of the area. The conditional probability tables (CPTs) of the indicator variables were acquired from these datasets by using the batch learning method provided by Hugin software (EM-algorithm, Lauritzen, 1995). This method enables estimating the conditional probability distributions based on a data set when only the graphical BN structure is given.

\subsection{Modelling the maximum growth depth of Fucus vesiculosus}

The brown alga Fucus vesiculosus L. (bladder wrack) is the only single species indicator used in the Finnish ESC approach. The ESC of F. vesiculosus is based on the maximum growth depth of the species compared with reference values. Based on a literature review, the most fundamental environmental elements affecting the occurrence of the species were found to be salinity (e.g., Serrão et al., 1996) and light (e.g., Bäck and Ruuskanen, 2000). The maximum growth depth of $F$. vesiculosus has distinct class boundaries and reference values for the different areas, in addition to those of the exposed and sheltered 
sites within them (Vuori et al., 2009). The definition of wave exposure of the site is based on the Baardseth-index (Ruuskanen and Bäck, 1999).

Data on $F$. vesiculosus growth depth from the years 1977-2005 and the corresponding water quality data was provided by the Finnish Environment Institute. The correlation of growth depth and underwater light conditions was assessed through the Secchi depth, which is closely correlated with eutrophication via algal base production. The Baardseth (1970) wave exposure indexes were determined for the $F$. vesiculosus observation sites on the map.

Simplified $F$. vesiculosus $\mathrm{BN}$ structures were included in the areal $\mathrm{BNs}$ as sub-models. The sub-model consists of the input node 'Secchi depth' from the areal model and the areal salinity node that provides information for two separate maximum growth depth nodes: one for exposed locations and another for sheltered shores (Figure 2). The compiled data were used to acquire the CPTs by using the batch learning.

\subsection{Definition of the general WFD status}

According to the WFD, the definition of the general status class of a certain area of water is based on the results of its biological, physical and chemical indicators. In Finland, the status estimation is based on the 'averaging rule' (Vuori et al., 2009) but, e.g., in Estonia the 'one out-all out' (OoAo) principle is used. The latter entails that an area is classified according to the indicator that gives the worst result. Furthermore, the method of averaging can produce different results depending on which statistic (mean or median) of the central tendency is used.

We wanted to compare the differences in the general picture that different methods produce. Therefore, we included all three of the above-mentioned approaches in the BN tool, so that the user can choose which one to use with the decision variable 'valuation approach' (Figure 2). This feature allows us to consider how likely the varying approaches lead to different management needs within the same area.

In the valuation approaches that were based on using means and medians the indicators were averaged by first assigning each status class a numerical value, which are provided in Vuori et al. (2009). These common factors (CF) describe the relative status of a class compared with the highest class, being 0.9 for 'high', 0.7 for 'good', 0.5 for 'moderate', 0.3 for 'poor' and 0.1 for 'bad'. The definition of the general status of an area was based on the mean (approach A) or the median (approach B) of the CFs of all indicators according to following intervals: 'high' $>0.8$, 'good' $\leq 0.8$, 'moderate' $\leq 0.6$, 'poor' $\leq 0.4$ and 'bad' $\leq 0.2$ (Vuori et al., 2009). In the third approach (approach C), the general status of the water area follows the OoAo rule. For example, in the case that one indicator is in the 'poor' state and the others are classified as 'good', the general status of the area is classified as 'poor'. Thus, the CFs are not needed in this case.

\subsection{Valuation of the end results}

The objective of the WFD is to attain at least a good ecological status. In the utility function of the BID, values for all the possible outcomes of the model have to be given. In this case, we did not use any monetary valuations, so we simply assigned the value 1 for all the cases for which the WFD objectives were fulfilled, i.e., the general status of the selected area (or the statuses of all the areas, if the alternative 'all areas' is selected) were either 'high' or 'good'. All the other possible outcomes were given the value of 0 . In this 
way, the resulting expected utilities can actually be interpreted directly as probabilities and the objective of our BN model is to find the strategy that maximises the probability of success in reaching 'good' or 'high' status.

\section{Results}

In this section, we present selected outputs of the $\mathrm{BN}$ as results of selected scenarios for area 4 (GoF outer archipelago) in addition to BN outputs for the whole Finnish coastal area. Different approaches that determine the general WFD status, i.e., approaches A, B and $\mathrm{C}$ are compared and the optimum routes for meeting the WFD objectives by the year 2015 are examined.

\subsection{Example scenarios}

The six scenarios presented are:

1 current nutrient loading and precipitation $(\mathrm{Sc} 0)$

2 current nutrient loading with increased precipitation (Sc1)

3 current nutrient loadings for Estonia and for Russia but an abatement scenario FIN3 for Finland (Sc2)

4 current nutrient loadings for Finland and for Russia but the scenario EST1 for Estonia ( $\mathrm{Sc} 3)$

5 current loadings for Finland and for Estonia but an abatement scenario RUS2 for Russia (Sc4)

6 the 'best case scenario' (Sc5), where the decision variables are set to the states that produce the MEU, i.e., all three countries implement maximal nutrient abatement (Table 2).

Table 2 Settings used in the six example scenarios for Finland, Estonia and Russia

\begin{tabular}{lcccc}
\hline \multirow{2}{*}{ Scenario } & Precipitation & \multicolumn{3}{c}{ National nutrient abatement scenarios } \\
\cline { 3 - 5 } & & Finland & Estonia & Russia \\
\hline 0 & Current level & Current level & Current level & Current level \\
1 & Increased & Current level & Current level & Current level \\
2 & Uniform distribution & FIN3 & Current level & Current level \\
3 & Uniform distribution & Current level & EST1 & Current level \\
4 & Uniform distribution & Current level & Current level & RUS2 \\
5 & Uniform distribution & FIN3 & EST1 & RUS2 \\
\hline
\end{tabular}

Note: Uniform distribution for precipitation means that both alternative states of the variable are handled as equally likely. 


\subsection{GoF outer archipelago (area 4)}

With the current state scenario $(\mathrm{Sc} 0)$ and averaging by mean (valuation approach $\mathrm{A}$ ), the most likely general WFD status for area 4 is 'moderate' $(p=79.82 \%)$ (Table 3, Figure 3). The state 'good' has the majority of residual probability mass $(19.31 \%)$. The probability for reaching the objective, i.e., the state of 'good' or 'high' $(\mathrm{p}=0.01 \%)$ by 2015 , is $19.32 \%$

Figure 3 Probability distributions of the predicted general WFD status for area 4 (GoF outer archipelago) under scenarios $0-5$ with three alternative valuation approaches $\mathrm{A}-\mathrm{C}$, (a) Approach A (means) (b) Approach B (medians) (c) Approach C (OoAo) (see online version for colours)

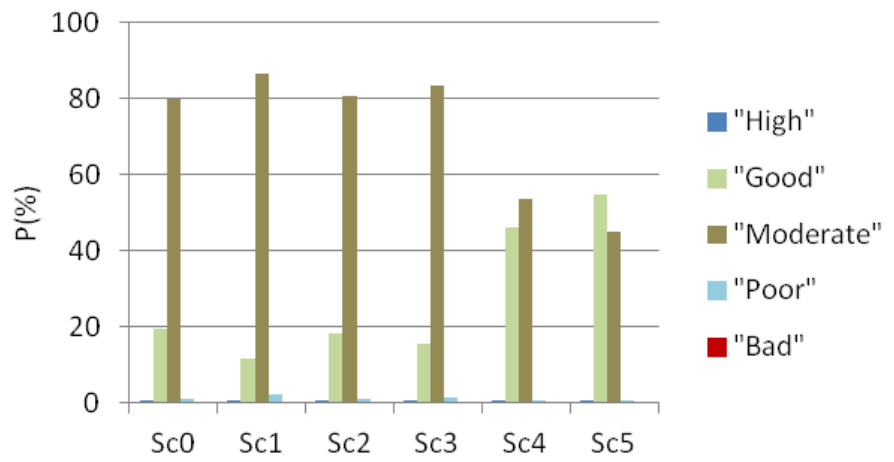

(a)

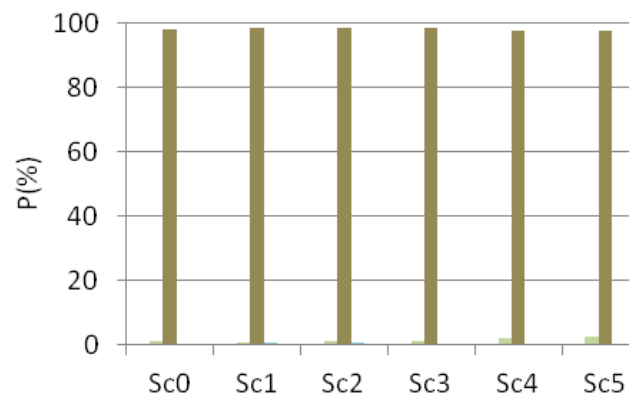

(b)

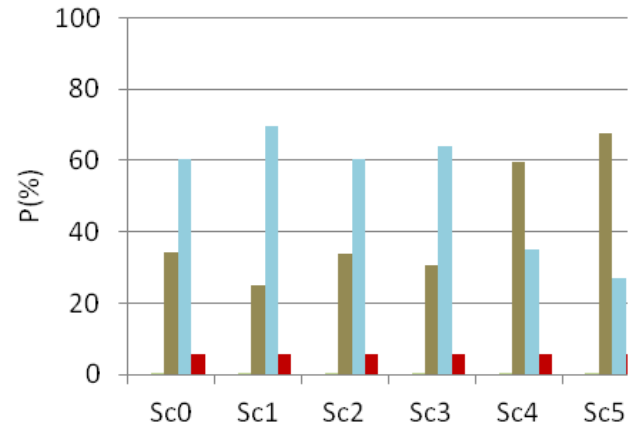

(c)

Note: Each probability distribution sums up to $100 \%$. 
Table 3 Probability distributions of the ecological status classes and the single indicators for area 4 (GoF outer archipelago) by using scenarios $\mathrm{Sc} 0$ and $\mathrm{Sc} 5$ and averaging by mean

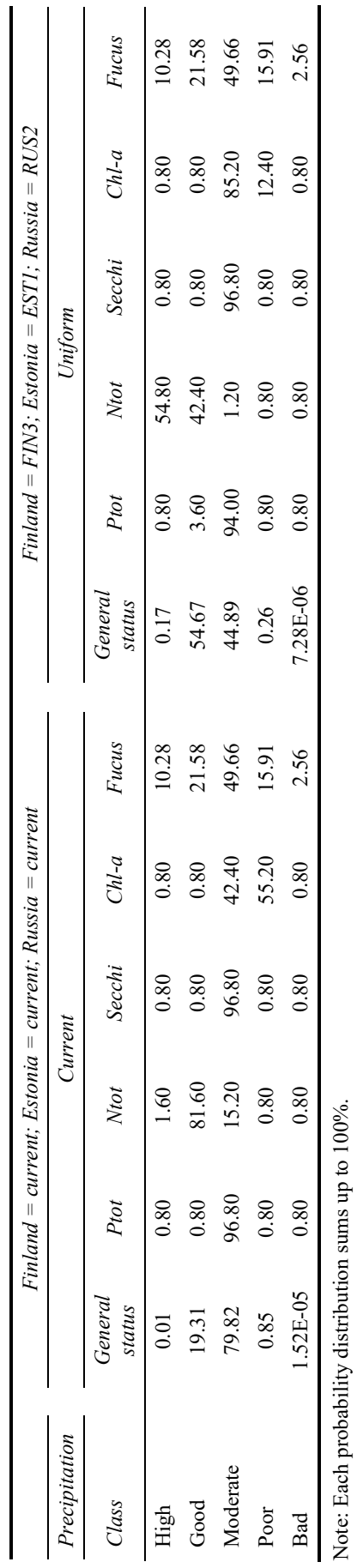


It seems that the separate indicator variables can give highly variable pictures of the status of the area in addition to the uncertainties related to it (Table 3). In practice, nutrients and Secchi depth are used only as supporting indicators (Vuori et al., 2009). For instance, if their results were to contradict the results of biological indicators such as chl- $a, F$. vesiculosus and benthic index (not included in this analysis tool so far), the biological indicators would determine the final status class. Of the total nutrients, phosphorus is used as the dominant factor in defining the general status. In the case of Sc0 (Table 3), total nitrogen lay out with the general line by having the majority of its probability mass in the state 'good' $(\mathrm{p}=81.60 \%)$, whereas total phosphorus, Secchi depth and $F$. vesiculosus all indicate the state 'moderate'. Chl- $a$, in turn, has the greatest probability mass in the 'poor' state $(\mathrm{p}=55.20 \%)$ although the probability for the 'moderate' state is quite high as well.

In this model, the status of $F$. vesiculosus is clearly the most uncertain, i.e., it has the widest probability distribution. It is also noteworthy that when it comes to the indicators Secchi and Fucus, all the differences between the scenarios seem to disappear within the class boundaries. This can be observed by comparing their distributions for $\mathrm{Sc} 0$ and $\mathrm{Sc} 5$ in Table 3 and could be seen as an artefact of the uninformative discretisation. The prevailing ESC approach with fixed class boundaries is discussed later in the text.

When examining the scenario-specific probability distributions for the general WFD status in area 4 (Figure 3), the state 'moderate' still remains the most likely outcome for scenarios 1-4 whereas 'good' is ranked second. The effect of increased precipitation can be studied by comparing the scenarios $\mathrm{Sc} 0$ and $\mathrm{Sc} 1$. Increased precipitation moves the probability mass slightly towards lower status classes. In the light of the uncertainty about the future development of the precipitation, the effects of even the most optimistic Finnish (Sc2) or Estonian ( $\mathrm{Sc} 3$ ) abatement measures seem to be quite small in comparison with the present situation. In contrast, the effect of the most potent Russian actions (Sc4) is clearly shown. Still, the only scenario that produces a higher probability for the 'good' state over that of the 'moderate' state in area 4 is Sc5 for which all three countries implement maximal abatement efforts (Table 3, Figure 3). However, if the precipitation for this scenario is set to the increased state, the status 'moderate' is again the more likely outcome $(p=56.83 \%)$ than 'good' $(p=42.76 \%)$.

The results with valuation approaches $\mathrm{B}$ and $\mathrm{C}$ differ from those of the $\mathrm{A}$ approach presented above. When averaging by median (approach B), 'moderate' is clearly the most probable state for all the scenarios (Figure 3). Moreover, the OoAo principle (approach C) gives quite different results compared with averaging (approaches A and B), as under this condition the probability distribution of the general status is skewed towards the worse states (Figure 3). For example, in scenario $\mathrm{Sc} 0$ describing the current state, the two most likely states are 'poor' $(p=60.18 \%)$ and 'moderate' $(p=34.21 \%)$. As only one indicator can turn the general state of an area to 'bad', a constant probability of around $5.60 \%$ for this state appears in each scenario.

\subsection{Expected utilities and the probability of not meeting the WFD objectives}

When considering all the areas together, the model produces highly variable results depending on the valuation approach used. With approach A (averaging by mean), fulfilling the objectives of the WFD is much more attainable in western areas (1 and 3) than in eastern areas (2 and 4) (Figure 4). Area 4 has the greatest probability of not reaching the goal. Even with the best case scenario (Sc5), the likelihood of reaching the 
target in area 4 is $55 \%$, meaning that the chance of failing is $45 \%$. The probability of reaching good ecological status by the year 2015 in the whole Finnish coastal area of the GoF seems very low, the probability of failing being almost $80 \%$ even in the best case scenario. The probabilities to reach the target are even smaller when averaging by median (approach B) (Figure 4). It also seems that the probability of failure is higher in the outer areas of the archipelago than in its inner areas.

Figure 4 Expected utilities (EU, scale 0-1) for separate areas and for all four areas together given six scenarios (0-5) when using the valuation approaches A and B, (a) Approach A (means) (b) Approach B (medians) (see online version for colours)

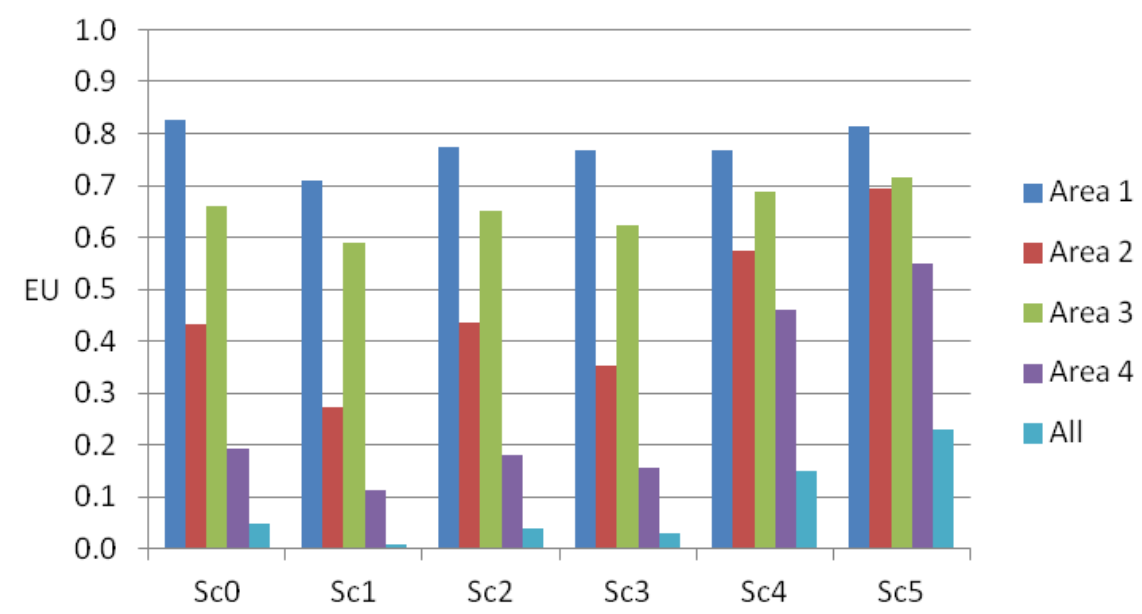

(a)

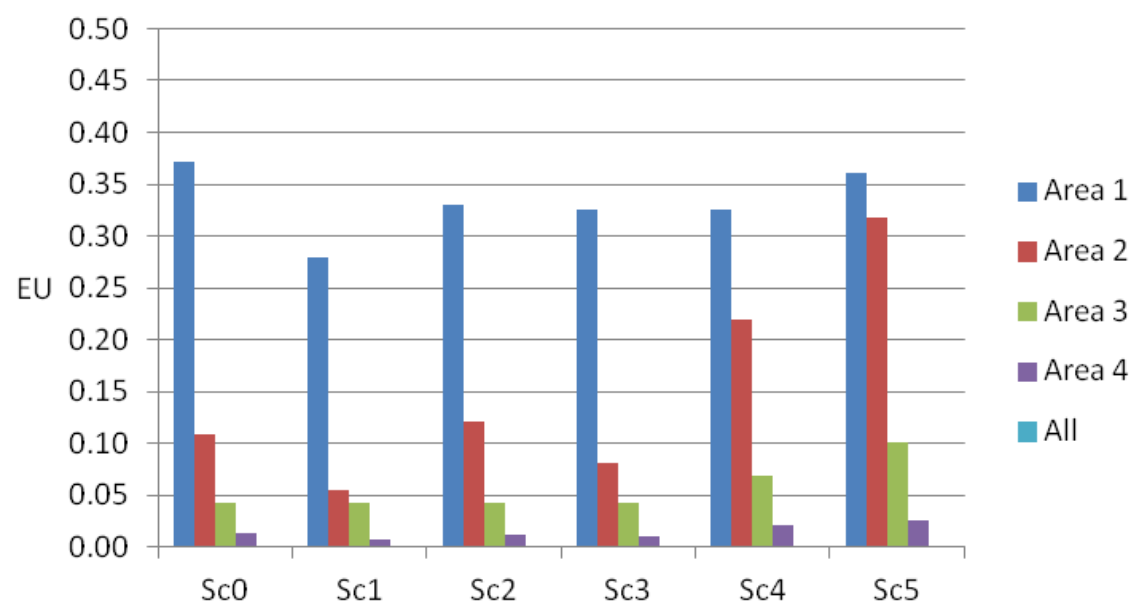

(b)

Notes: In this case, the EU value is proportional to the probability of reaching the objectives of the WFD by the year 2015 in each case. Note the different scales on y-axes. 
The results of the valuation approach $\mathrm{C}$ (OoAo) differ substantially from the outcomes produced by $\mathrm{A}$ and $\mathrm{B}$ methods. The probability of attaining the objective for the best case scenario (Sc5) in area 4 is $5.6 \times 10^{-5} \%$ the probability of failing thus being close to $100 \%$. For the whole coast (areas 1-4), with the best case scenario, the probability is as low as $2.26 \times 10^{-11} \%$. With this approach, the goal of WFD seems to be nearly impossible to reach.

\section{Discussion}

We have described a prototype of a decision analysis tool, which can be used to assess the probability of attaining the WFD objectives in the Finnish coastal waters of the GoF under certain selected national nutrient abatement scenarios (Lindén et al., 2007). The tool uses multiple indicators to enable the assessment of uncertainties related to an ecosystem's state and calculates the likely effects of alternative decisions on nutrient abatement made for that ecosystem. The results suggest that very significant reductions in nutrient loads would be required to achieve a good ecological status in the coastal waters of the GoF, and with increased precipitation and run-off the target may be even more difficult to achieve.

The current version of the model indicates that the goals of the WFD in Finnish coastal waters of the GoF being reached by 2015 is very unlikely. Even with the very roughly defined abatement measures considered here, it is evident that much co-ordinated effort will be needed by all countries surrounding the gulf to improve the state of the coastal waters. In practice, annual nutrient loads of total nitrogen and total phosphorus from Finland have not shown any clear trends or consistent changes after the early 2000s. Although point-loads of nitrogen decreased by about 1,000 t/a, no actual trends can be seen in total loading due to substantial year to year variation in riverine loads that are strongly affected by variations in precipitation and diffuse loading (HELCOM, 2011). However, phosphorus loading from the St. Petersburg region decreased by about 1,700 t/a after the early 2000s (Vodokanal of St. Petersburg, 2013). This decrease is clearly more than that calculated for the 'all treated scenario' for Russia (RUS2) in our model and has evidently caused a decreasing trend in the total Russian phosphorus load into the GoF.

Our study demonstrates that diverse approaches to evaluating WFD ESC produce highly varying results. The model clearly illustrates differences between the averaging and 'OoAo' principles as valuation approaches. Averaging by mean gives the most positive picture of the ecosystem state under varying conditions, mainly because of the high status classes in the case of nitrogen, whereas the OoOa approach gave the most pessimistic outcomes. The current Finnish classification system is based on averaging by median (Vuori et al., 2009), which in our study resulted in classifications between the other two approaches.

Different methods that integrate the knowledge about variables considered in the WFD ESC have been studied in freshwater ecosystems (Søndergaard et al., 2005; Alahuhta et al., 2009; Rask et al., 2011), but studies conducted in coastal environments are scarce. It is important to note that different approaches not only produce different absolute values but also alter the order in which the Finnish WFD areas changes relative to each other, when the effectiveness of nutrient abatement scenarios is considered 
(Figure 4). Therefore, our study demonstrates that the choice of the WFD classification approach should be done carefully and in a well-researched way.

The modelling approach used in this study has many advantageous features. The model combines knowledge from several complex models, the results of which may otherwise be too difficult for decision-makers to interpret or to use in an interactive manner. The model allows 'what if' type of questions to be used and it is also easy and quick to use. As the model structure is fairly simple, some might consider it as an oversimplification of the ecosystem. Consequently, we stress that the focus of this article is not to present a detailed nutrient drift model but simulation models of that kind were used for teaching a BN the dependencies between the variables. We wanted to develop a decision analysis tool for studying our possibilities to gain the objectives of the WFD. This tool had to take into account such uncertainties as the unknown future development of precipitation and also the inherent variability in the observations encountered for the same area. As a whole, the model is a representation of expert knowledge and also considers events that are possibilities that have not yet happened. Thus, direct validation against existing objective data is not possible. However, it would be possible to examine the internal consistency of the model (O'Hagan et al., 2006; Pitchforth and Mengersen, 2013). It would also be possible to recognise other issues that are believed to exist in the real world but which are not accounted for in the current model. We highlight these in the following paragraphs.

The model does not perfectly mimic the WFD status classification in practice. One clear imperfection is the absence of the benthic index (Perus et al., 2007; Vuori et al., 2009), which is one of the biological and thus principal weighted indicator quantities used in Finland. Oxygen depletion and the consequent death of benthic fauna are major problems in many parts of the GoF (Pitkänen et al., 2003). Therefore, adding a benthic index to the model would probably improve its predictions. In addition, it is important to note that the presented model in its current form has been developed to predict the computational WFD status classifications. In reality, the classification in Finland is done by a more case-specific approach. When defining the ecological status of a coastal water zone the result only partly depends on the computational standard values. In addition, the status is evaluated by experts including the evaluation of reliability and representativeness of the monitoring data used (Vuori et al., 2009). This has not been taken into account in the present model, although the characteristics of the BNs would enable us to complement the approach in that direction. However, the current version offers a likely indication of the future situation under alternative circumstances. Therefore, decision-makers and researchers working with the classification of coastal waters will also be able to use it as a supporting tool.

The WFD requires monitoring results to provide acceptable levels of confidence and precision, taking into account the inherent seasonal and spatial variability (Irvine, 2004). Irvine (2004) emphasises that monitoring that fails to factor in seasonal and spatial variation is useless. He also states that too little effort has been put on the analyses of regional variation in many programmes, as the process of collecting and analysing the samples is costly. In our model, the uncertainties in the indicators arise from the spatial variability in the simulation model results, and also by precipitation. Our model could be further developed to be utilised for making inferences about the likely spatial and temporal variability in the indicators.

Using a deterministic simulation model as the EIA-SYKE model for teaching a BN the conditional dependencies between the variables is quite tedious. Each of the possible 
scenario combinations that the network structure produces needs to be simulated one by one. Dorner et al. (2007) converted a process model of erosion and sedimentation into a $\mathrm{BN}$ format. Those authors reported that the resulting model produced the same outputs as the original model with the same input data. They recommend this type of approach to be used for those cases in which the objective of the modelling is for decision support purposes, rather than on the detailed analysis of physical processes. Compared with the computationally laborious simulation model, the efficiency and speed of the $\mathrm{BN}$ for scenario exploration is unchallenged. The user can also interact directly with the BNs, as the results are almost immediately available. We think that models such as the one presented in this paper can be also used as the basis when planning larger simulation series. They provide useful guidelines when searching for the best sets of the model runs such as when predicting the likely effects of more detailed management action plans.

One interesting aspect from the decision analysis point of view is the uncertainties related to the criteria, i.e., the target states in this study. We applied the class boundaries that are currently in use (Vuori et al., 2009), and thus we did not add any uncertainty to the classification system. However, there are no absolute ways to determine the boundary values, and in reality the limits between the classes are vague. A recent review of assessment methods related to the WFD in Europe, was carried out by Birk et al. (2012). Those authors pointed out that the majority of classifications in Europe are based on statistical approaches instead of ecological principles, thus the boundaries may not correspond to biologically meaningful changes in ecosystems. Further, Fernandes et al. (2012) studied the probabilities to achieve the 'good' state for nutrients and chl- $a$ in the GoF simultaneously, and concluded that the weak dependency between the studied metrics may result from a non-harmonised target-setting, which does not allow for dependencies, variability and uncertainty. Our results suggest that the inclusion of uncertainty in the present classifications may be justified.

According to Irvine (2004), the fixed-boundary classification schemes are found to be insensitive to the realities of spatial and seasonal variance. That author called for the incorporation of the risk of misclassification when designing and evaluating the results of WFD monitoring programmes. BNs provide one possible method to do that. We should be especially interested in the limit between 'good' and 'moderate' states, since the difference of only one unit may move a watershed from the acceptable state to one needing costly restoration operations. In practice, with the current version of our model, all the uncertainty in the indicators can be seen to arise from the spatial variability of those values within the areas when all the decision variables and precipitation scenario are set to 'known' states. Thus, we could also use our model for analysing the risk of misclassification by which the uncertainty that arises from the spatial variability in the monitoring data is likely to produce.

To conclude, the model presented in this paper offers one possible solution to the widely recognised problem about the challenges to decision-making when available information is complex and the uncertainties high. Although the nutrient reduction scenarios in our model are fairly coarse, the idea can also be applied to more realistic and elaborate management options, which enables the comparison of potentially conflicting measures. At its best, this type of application could serve as a support tool for the trans-border cooperation in the research planning and conservation of the coastal waters. 


\section{References}

Aguilera, P.A., Fernandez, A., Fernandez, R., Rumi, R. and Salmeron, A. (2011) 'Bayesian networks in environmental modelling', Environmental Modelling and Software, Vol. 26, No. 12, pp.1376-1388.

Alahuhta, J., Vuori, K-M., Hellsten, S., Järvinen, M., Olin, M., Rask, M. and Palomäki, A. (2009) 'Defining the ecological status of small forest lakes using multiple biological quality elements and palaeolimnological analysis', Fundamental and Applied Limnology, Vol. 175, No. 3, pp.203-216.

Baardseth, E. (1970) 1 A Square-scanning, Two Stage Sampling Method of Estimating Seaweed Quantities, Report 33, pp.1-41, Norwegian Institute for Seaweed Research.

BACC Author Team (2008) Assessment of Climate Change for the Baltic Sea Basin. Regional Climate Studies, Springer-Verlag, Berlin, Heidelberg.

Bäck, S. and Ruuskanen, A. (2000) 'Distribution and maximum growth depth of Fucus vesiculosus along the Finnish coastline', Marine Biology, Vol. 136, No. 2, pp.303-307.

Birk, S., Bonne, W., Borja, A., Brucet, S., Courrat, A., Poikane, S., Solimini, A., van de Bund, W., Zampoukas, N. and Hering, D. (2012) 'Three hundred ways to assess Europe's surface waters: an almost complete overview of biological methods to implement the water framework directive', Ecological Indicators, Vol. 18, pp.31-41.

Borsuk, M.E., Craig, A.S. and Reckhow, K.H. (2004) 'A Bayesian network of eutrophication models for synthesis, prediction and uncertainty analysis', Ecological Modeling, Vol. 173, Nos. 2-3, pp.219-239.

Bromley, J., Jackson, N.A., Clymer, O.J., Giacomello, A.M. and Jensen, F.V. (2005) 'The use of Hugin ${ }^{\circledR}$ to develop Bayesian networks as an aid to integrated water resource planning', Environmental Modeling and Software, Vol. 20, No. 2, pp.231-242.

Burgman, M.A. (2005) Risks and Decisions for Conservation and Environmental Management, Cambridge University Press, Cambridge.

Cain, J.D., Jinapala, K., Makin, I.W., Somaratna, P.G., Ariyaratna, B.R. and Perera, L.R. (2003) 'Participatory decision support for agricultural management: a case study from Sri Lanka', Agricultural Systems, Vol. 76, No. 2, pp.457-482.

Chen, S.H. and Pollino, C.A. (2012) 'Good practice in Bayesian network modelling', Environmental Modelling and Software, Vol. 37, pp.134-145.

De Wit, M.J.M. (2001) 'Nutrient fluxes at the river basin scale', Hydrological Processes, Vol. 15, No. 5, pp.43-759.

Dorner, S., Shi, J. and Swayne, D. (2007) 'Multi-objective modeling and decision support using a Bayesian network approximation to a non-point source pollution model', Environmental Modelling \& Software, Vol. 22, No. 2, pp.211-222.

Elken, J., Golubkov, S., Pitkänen, H. and Sarkkula, J. (2003) 'Special issue on the changing state of the Gulf of Finland', Proceedings of the Estonian Academy of Sciences: Biology/Ecology, Vol. 52, 362p.

European Commission (2000) Directive 2000/60/EC of the European Parliament and of the Council of 23 October 2000 Establishing a Framework for Community Action in the Field of Water Policy, Official Journal L327/1.

Fenton, N. and Neil, M. (2001) 'Making decisions: using Bayesian nets and MCDA', Knowledge-based Systems, Vol. 14, No. 7, pp.307-325.

Fernandes, J.A., Kauppila, P., Uusitalo, L., Fleming-Lehtinen, V., Kuikka, S. and Pitkänen, H. (2012) 'Evaluation of reaching the targets of the water framework directive in the Gulf of Finland', Environmental Science \& Technology, Vol. 46, No. 15, pp.8220-8228.

Gilks, W.R., Thomas, A. and Spiegelhalter, D.J. (1994) 'A language and program for complex Bayesian modelling', The Statistician, Vol. 43, No. 1, pp.169-177.

HELCOM (2005) 'Nutrient pollution to the Baltic Sea in 2000', Baltic Sea Environment Proceedings, No. 100, 24p. 
HELCOM (2011) 'Fifth Baltic Sea pollution load compilation (PLC-5)', Baltic Sea Environment Proceedings, No. 128, 217p.

Irvine, K. (2004) 'Classifying ecological status under the European water framework directive: the need for monitoring to account for natural variability (editorial)', Aquatic Conservation: Marine and Freshwater Ecosystems, Vol. 14, No. 2, pp.107-112.

Jensen, F.V. (2001) Bayesian Networks and Decision Graphs, Springer-Verlag, New York.

Kiirikki, M., Inkala, A., Kuosa, H., Pitkänen, H., Kuusisto, M. and Sarkkula, J. (2001) 'Evaluating the effects of nutrient load reductions on the biomass of toxic nitrogen-fixing cyanobacteria in the Gulf of Finland, Baltic Sea', Boreal Environment Research, Vol. 6, pp.131-146.

Kiirikki, M., Lehtoranta, J., Inkala, A., Pitkänen, H., Hietanen, S., Hall, P.O.J., Tengberg, A., Koponen, J. and Sarkkula, J. (2006) 'A simple sediment process description suitable for 3D-ecosystem modeling - development and testing in the Gulf of Finland', Journal of Marine Systems, Vol. 61, Nos. 1-2, pp.55-66.

Kjærulff, U.B. and Madsen, A.L. (2005) Probabilistic Networks - An Introduction to Bayesian Networks and Influence Diagrams [online] http://www.cs.aau.dk/ uk/papers/pgm-book-I05.pdf (accessed 28 March 2013).

Kuikka, S. and Varis, O. (1997) 'Uncertainties of climatic change impacts in Finnish watersheds: a Bayesian network analysis of expert knowledge', Boreal Environmental Research, Vol. 2, No. 1, pp.109-128.

Lauritzen, S.L. (1995) 'The EM algorithm for graphical association models with missing data', Computational Statistics \& Data Analysis, Vol. 19, No. 2, pp.191-201.

Lehikoinen, A., Luoma, E., Mäntyniemi, S. and Kuikka, S. (2013) 'Optimizing the recovery efficiency of Finnish oil combating vessels in the Gulf of Finland using Bayesian networks', Environmental Science and Technology, Vol. 47, No. 4, pp.1792-1799.

Lindén, E., Lehikoinen, A., Kuikka, S., Aps, R., Kotta, J., Martin, G., Saat, T., Pitkänen, H., Räike, A., Korpinen, P., Stipa, T., Kaitala, S. and Jolma, A. (2007) EVAGULF - Protection of Aquatic Communities in the Gulf of Finland: Risk-based Policymaking, ICES CM Documents 2007/C:07. http://info.ices.dk/products/CMdocs/CM-2007/CM2007.pdf (accessed 28 March 2013).

Lindén, E., Lehikoinen, A., Kuikka, S., Aps, R., Kotta, J., Pitkänen, H., Korpinen, P., Räike, A., Stipa. T., Kaitala, S., Niiranen, S. and Jolma, A. (2008) EVAGULF - Protection of Aquatic Communities in the Gulf of Finland: Risk-based Policymaking, Final report [online] http://www.helsinki.fi/science/fem/articles/evagulffinalreport.pdf (accessed 28 March 2013).

Madsen, A.L., Jensen, F., Kjærulff, U.B. and Lang, M. (2005) 'The Hugin tool for probabilistic graphical models', International Journal on Artificial Intelligence Tools, Vol. 14, No. 3, pp.507-543.

Mäntyniemi, S. (2006) Bayesian Fisheries Stock Assessment: Integrating and Updating Knowledge, $\mathrm{PhD}$ thesis, University of Helsinki, Helsinki, Finland.

Mäntyniemi, S., Haapasaari,P., Kuikka, S., Parmanne, R., Lehtiniemi, M. and Kaitaranta, J. (2013) 'Incorporating stakeholders' knowledge to stock assessment: Central Baltic Herring', Canadian Journal of Fisheries and Aquatic Sciences, Vol. 70, No. 4, pp.591-599, DOI: 10.1139/cjfas-2012-0316.

O'Hagan, A., Buck, C.E., Daneshkhah, A., Eiser, J.R., Garthwaite, P.H., Jenkinson, D.J., Oakley, J.E. and Rakow, T. (2006) Uncertain Judgments: Eliciting Experts' Probabilities, Wiley, Chichester.

Perus, J., Bonsdorff, E., Bäck, S., Lax, H.G., Villnäs, A. and Westberg, V. (2007) 'Zoobenthos as indicators of ecological status in coastal brackish waters: a comparative study from the Baltic Sea', Ambio, Vol. 36, No. 2, pp.250-256

Pinheiro, P.R., de Castro, A.K.A. and Pinheiro, M.C.D. (2008) 'A multi-criteria model applied in the diagnosis of Alzheimer's disease: a Bayesian network', 2008 IEEE 11th International Conference on Computational Science and Engineering (CSE 2008), pp.15-22. 
Pitchforth, J. and Mengersen, K. (2013) 'A proposed validation framework for expert elicited Bayesian networks', Expert Systems with Applications, Vol. 40, No. 1, pp.162-167.

Pitkänen, H. and Tallberg, P. (2007) Searching Efficient Protection Strategies for the Eutrophied Gulf of Finland: The Integrated Use of Experimental and Modelling Tools (SEGUE), Final Report, Finnish Environment 15/2007.

Pitkänen, H., Lehtoranta, J., Peltonen, H., Laine, A., Kotta, J., Kotta, I., Moskalenko, P., Mäkinen, A., Kanhas, P., Perttilä, M. and Kiirikki, M. (2003) 'Benthic release of phosphorus and its relation to environmental conditions in the estuarial Gulf of Finland, Baltic Sea, in the early 2000s', Proceedings of the Estonian Academy of Sciences. Biology/Ecology, Vol. 52, No. 3, pp.173-192.

Power, M. and McCarty, L.S. (2006) 'Environmental risk management decision-making in a societal context', Human and Ecological Risk Assessment, Vol. 12, No. 1, pp.18-27.

Rask, M., Vuori, K-M., Hämäläinen, H., Järvinen, M., Hellsten, S., Mykrä, H., Arvola, L., Ruuhijärvi, J., Jyväsjärvi, J., Kolari, I., Olin, M., Salonen, E. and Valkeajärvi, P. (2011) 'Ecological classification of large lakes in Finland: comparison of classification approaches using multiple quality elements', Hydrobiologia, Vol. 660, No. 1, pp.37-47.

Reckhow, K.H. (1999) 'Water quality prediction and probability network models', Canadian Journal of Fisheries and Aquatic Sciences, Vol. 56, No. 7, pp.1150-1158.

Rekolainen, S., Vuoristo, H., Kauppi, L., Bäck, S., Eerola, M., Jouttijärvi, T., Kaukoranta, E., Kenttämies, K., Mitikka, S., Pitkänen, H., Polso, A., Puustinen, M., Rautio, L. M., Räike, A., Räsänen, J., Santala, E., Silvo, K. and Tattari, S. (2006) Reducing Nutrient Loads to the Surface Waters, Background Study Part I, Guidelines for Water Protection to 2015, Reports of Finnish Environment Institute 22/2006 (in Finnish, English summary).

Ruuskanen, A. and Bäck, S. (1999) 'Does environmental stress affect fertility and frond regeneration of Fucus vesiculosus?', Annales Botanici Fennici, Vol. 36, No. 4, pp.285-290.

Sedki, K., Delcroix, V., Lepoutre, F., Adam, E., Maquinghen-Godillon, A. and Ville, I. (2010) 'Bayesian network model for decision problems', in Kłopotek, M.A., Marciniak, M., Mykowiecka, A., Penczek, W. and Wierzchoń, S.T. (Eds.): Proceedings of International Conference of Intelligent Information Systems 2010, pp.285-298, ISBN 978-83-7051-580-5.

Serrão, E.A., Kautsky, L. and Brawley, S.H. (1996) 'Distributional success of the marine seaweed Fucus vesiculosus L. in the brackish Baltic Sea correlates with osmotic capabilities of Baltic gametes', Oecologia, Vol. 107, No. 1, pp.1-12.

Sigel, K., Klauer, B. and Pahl-Wostl, C. (2010) 'Conceptualising uncertainty in environmental decision-making: the example of the EU water framework directive', Ecological Economics, Vol. 69, No. 3, pp.502-510.

Søndergaard, M., Jeppesen, E., Jensen, J.P. and Amsinck, S.L. (2005) 'Water framework directive: ecological classification of Danish lakes', Journal of Applied Ecology, Vol. 42, No. 4, pp.616-629.

Soomere, T., Myrberg, K., Leppäranta, M. and Nekrasov, A. (2008) 'The progress in knowledge of physical oceanography of the Gulf of Finland: a review for 1997-2007', Oceanologia, Vol. 50, No. 3, pp.287-362.

Uusitalo, L., Kuikka, S. and Romakkaniemi, A. (2005) 'Estimation of Atlantic salmon smolt carrying capacity of rivers using expert knowledge', ICES Journal of Marine Science, Vol. 62, No. 4, pp.708-722.

Varis, O. (1997) 'Bayesian decision analysis for environmental and resource management', Environmental Modeling \& Software, Vol. 12, Nos. 2-3, pp.177-185.

Varis, O., Kettunen, J. and Sirviö, H. (1990) 'Bayesian influence diagram approach to complex environmental management including observational design', Computational Statistics and Data Analysis, Vol. 9, No. 1, pp.77-91.

Vodokanal of St. Petersburg (2013) http://www.vodokanal.spb.ru/en/kanalizovanie/ekologiya_ baltijskogo_morya (accessed 28 March 2013). 
Vuori, K-M., Mitikka, S. and Vuoristo, H. (Eds.) (2009) Guidance on Ecological Classification of Surface Waters in Finland, Environmental Administration Guidelines 3/2009 (in Finnish, English summary).

Watthayu, W. and Peng, Y. (2004) 'A Bayesian network based framework for multi-criteria decision making', MCDM 2004: Proceedings of the 17th International Conference on Multiple Criteria Decision Analysis, the 17th International Conference on Multiple Criteria Decision Making. 